\title{
La nación en la televisión informativa colombiana: 1960 y 2015. Del infractor inexistente al enemigo omnipresente
}

\author{
The Nation in Colombian Television Newscasts: 1960 versus 2015. From \\ the Fictitious Offender to the Omnipresent Enemy
}

\author{
A nação na televisão informativa colombiana: 1960 e 2015. Do infrator \\ inexistente ao inimigo omnipresente
}

\author{
Ancízar Narváez Montoya ${ }^{1}$ \\ Ana Carmenza Romero Peña ${ }^{2}$
}

\section{Resumen}

El artículo expone un adelanto de los resultados del proyecto Educación mediática y nación en Colombia: la narración y la institucionalización 'audiovisual'. Se trata de diferenciar entre la manera como se narra la nación en los noticieros televisivos colombianos de los años sesenta (Actualidad panamericana) y la manera como se narra en los de hoy (Noticias rcn). Para ello, se analiza la narración mediática de la nación en los informativos televisivos de los años sesenta y en los actuales, desde cuatro aspectos contemplados por la teoría de los códigos: sustancias expresivas, formas expresivas, formas de contenido y sustancias de contenido. De estos aspectos, solo se expone aquí lo relacionado con la sustancia del contenido. Se establece una comparación entre las formas de representar, pero sobre todo entre lo representado como nación, en la televisión informativa en dos momentos de su desarrollo separados por más de 50 años.

Palabras clave

mediación; mediatización; cultura mediática; educación mediática; narración televisiva

Abstract

This paper is an advance of the research project entitled Media education and nation in Colombia-narration and "audiovisual" institutionalization. The purpose of the research is to distinguish between how the nation is narrated in the Colombian television newscasts of the 60's (Actualidad panamericana) and how it is narrated in current newscasts (Noticias RCN). For that purpose, the authors analyze the media narrative of the nation in television news broadcasted both during the sixties and recently, according to four aspects included in the code theory, namely: expressive substance, expressive forms, content forms, and content substances. The paper only deals with the latter. Authors compare the ways to represent-mostly what is represented as nation-, in television newscasts at two different moments in time, more than fifty years apart.

Keywords

mediation; media coverage; media culture; media education; television narrative

Resumo

0 artigo apresenta um avanço dos resultados do projeto Educação mediática e nação na Colômbia: a narração e a institucionalização 'audiovisual'. Trata-se de diferenciar entre a forma como é narrada a nação nos noticiários televisivos colombianos desde os anos sessenta (Actualidad panamericana) e a forma na que é narrada atualmente (Noticias RCM). Para isso, analisa-se a narração mediática da nação nos noticiários dos anos sessenta e nos atuais desde quatro aspectos contemplados pela teoria dos códigos: sustâncias expressivas, formas expressivas, formas de conteúdo e sustâncias de conteúdo. Destes aspectos, só é apresentado aquilo relacionado com a sustância do conteúdo. Estabelece-se uma comparação entre as formas de representar, mas especialmente entre o representado como nação, na televisão informativa em dois momentos de seu desenvolvimento separados por mais de 50 anos.

Palavras chave

mediação; midiatização; cultura mediática; educação mediática; narração televisiva

Artículo recibido el 2 de abril del 2016 y aprobado el 21 de diciembre del 2016

1 Profesor titular de la Universidad Pedagógica Nacional, Bogotá, Colombia. Correo electrónico: anarvaez@pedagogica.edu.co

2 Profesora de la Universidad Pedagógica Nacional, Bogotá, Colombia. Correo electrónico: anacromerop@gmail.com 


\section{Introducción}

En el marco de la discusión planteada por la línea de investigación en Educación-comunicación y dentro del macroproyecto sobre Educación mediática y nación, el problema que se ha planteado quiere empezar a responder a la siguiente pregunta: ¿cuál podría ser la relación entre la narración de la nación que construyen los medios de comunicación audiovisual y la conformación de una "cultura nacional" en Colombia? Más específicamente, ¿cómo ha podido contribuir la narración mediática audiovisual de la nación a la conformación de un relato y una cultura nacionales en Colombia?

\section{Algunos antecedentes}

Además del trabajo de Narváez y Arbeláez (2013, 2014), el cual se refiere específicamente a la radio pública y privada, muchos autores en Colombia se han referido a la información en televisión, desde Herrán (1991), hasta Carrillo y Montaña (2006), pasando por López de la Roche (2004) y su dossier sobre historia de los medios y del periodismo.

El trabajo de Zapata y Ospina (2004) es por derecho propio el primer referente para los antecedentes relacionados con los estudios de televisión en Colombia; es algo como un estado del arte de los estados del arte. Sin embargo, lo que interesa para efectos de este proyecto es lo relacionado con la evolución de los géneros, una manera de historiar la televisión especialmente pertinente para nuestros propósitos.

Después de la telenovela, los informativos son el género estrella de la televisión. Es la "historia en imágenes y sonidos". Las autoras encuentran dos tendencias en su estudio: la que resalta el carácter comercial, o sea su adscripción a los patrocinadores, cuyo caso emblemático es el "Reporter Esso", y la que critica a la adjudicación por reparto político, como una continuación del Frente Nacional, por lo que en los noticieros no quedaría la historia del país sino la del partido al que pertenece el noticiero.

Sin embargo, estas historias son bastante anecdóticas y no ofrecen en general análisis comunicacional de los géneros sino su lugar en la programación y su éxito de audiencia y acaso comercial, además del análisis político e ideológico que prima en el de los informativos.

Para este trabajo es de especial interés la información relacionada con el noticiero Actualidad Panamericana (Carrillo y Montaña, 2006), sobre todo por su carácter empresarial, pues desde el punto de vista de las fuentes, nosotros nos ocupamos del material fílmico:

En 1956, Álvaro Escallón Villa, Eduardo Caballero Calderón y Gregorio Espinosa fundan Panamerican Films, empresa que contaba con instalaciones y equipos propios, dedicada a la producción de cortos y documentales, pero principalmente del noticiero Actualidad Panamericana, que empezó a emitirse el 12 de diciembre de 1956. Actualidad Panamericana, sin lugar a dudas, constituyó el noticiero cinematográfico con la producción más sistemática; se trataba de un informativo semanal que recogía eventos políticos, reportajes turísticos, crónicas y acontecimientos deportivos y notas sobre la historia y desarrollo de empresas industriales y comerciales, que a la postre constituyeron la principal fuente de financiamiento por la publicidad que aparecía, abierta o soterradamente, en el noticiero. (p. 140).

En efecto, como veremos en el análisis de dicho material, fuera de los acontecimientos políticos sus principales protagonistas son los agentes empresariales.

Es reiterada la insistencia en la relación tecnología-narrativa. A este respecto, se hace una clara confesión de la continuidad de la última ante el cambio de la primera:

"La puesta en escena coincidía en muchos aspectos con el cine, en lo relacionado con la locución del narrador, cuya voz conducía al tele-espectador, mientras la imagen aparecía como un complemento visual del discurso informativo" (p. 139). Según las investigadoras, "para ese momento los periodistas eran más locutores que reporteros ya que estos narraban aún las noticias con los lenguajes propios de la radio y el cine" (p. 143). A este fenómeno se le sigue llamando "presentador ventrílocuo" y no es del todo ajeno a la presentación actual. 
Asimismo, algunos aspectos del contenido son resaltados en común con ciertos trabajos: "difícilmente se encuentran, en los informativos, voces disidentes o contrarias a las versiones oficiales" (p. 141). En todo caso, los atisbos de análisis de la narrativa y de la imagen no alcanzan a ser un análisis comunicacional en términos de la teoría de los códigos, como pretende el presente proyecto.

Lo más próximo a nuestra propuesta está en el trabajo de Acosta (2004), en el cual es posible identificar la narración informativa que hacen los Acevedo a través de su noticiero cinematográfico como una que va en cuatro ejes: medios-nación, medios-cultura, medios-modernidad, mediosmasificación. Dichos noticieros son los antecesores directos del material analizado por nosotros y el análisis de la autora, una lectura de cómo los medios, a través de estos textos en particular, elaboran una noción de nación:

a. Nación integrada a través de la aparición en los medios de varias regiones del territorio nacional.

b. La cultura que aparece en los medios como la cultura legítima.

c. La industrialización y el consumo que aparece en los medios como lo moderno.

d. La cultura de masas como la cultura moderna opuesta a la premoderna.

Aunque la autora da algunos saltos que no se respaldan en evidencias, como que la cultura alfabética es la que aparece en los medios como legítima $y$, por tanto, "lo popular se convierte en una forma de resistencia que polariza aún más las diferencias y evidencia la exclusión" (Acosta, 2004, p. 73) (pese a que lo que se puede ver es la legitimación de la cultura popular a través de la masificación mediática), es muy importante la siguiente conclusión:

Encontramos que las constantes identificadas para (sic) la producción informativa y comercial de los Acevedo entre 1940 y 1960 comparten características con la producción informativa actual: la televisión privilegia la información de entretenimiento, reproduce los discursos económicos y políticos hegemónicos y, por lo tanto, se enfrenta con grandes problemas para cubrir los temas relacionados con el conflicto armado. (p. 79).

Entonces aquí el análisis vuelve al contenido manifiesto, a los temas, al papel de los medios como instituciones y no a la narrativa. Además, hay algo de abuso en la utilización reiterada de la noción de hegemonía sin llegar a precisar su contenido. No obstante, más allá de este consenso en torno a que los medios, y en especial la televisión, son parte del entramado institucional del Estado para comunicarse, influir, educar, culturizar, etc., a la nación, lo que se mantiene es la creencia de que este medio puede sustituir a la alfabetización, como lo veía el director de la Biblioteca Nacional en 1936, quien creía que el cine, por impresionar la mentalidad de cualquier público

con más vigor que la simple (sic) lectura de un libro o de un cuadro de estadística, es el vehículo más eficaz para llevar la cultura a la escuela, a la sala comunal, a la aldea remota, a las masas populares, en un palabra. (Citado en Uribe Sánchez, 2004, p. 39).

¿Cómo no iba a serlo entonces la televisión que lograba poner en un mismo texto la puesta en escena del teatro, la voz y el sonido de la radio, y la imagen en movimiento del cine? Lo más llamativo es que es casi exactamente lo mismo que piensan hoy, 80 años después, muchos estudiosos de la educación y la comunicación, sin preguntarse siquiera por qué la escuela no ha desaparecido ni los libros, ni los cuadros estadísticos. Es aquí donde entra nuestro interés por los códigos.

\section{Lo mediático y las nuevas fuentes de identidad}

Recientemente se habla de relatos y memorias leves de nación, una suerte de falsas identidades con las cuales nos solazamos los colombianos ante la falta de un mito nacional fuerte $y$, sobre todo, verdadero. Rincón (2001) habla de una colombianidad hecha de fragmentos y de levedades, es decir, orgullos pasajeros y efímeros. Por ejemplo, "Amables, inventivos y caóticos; pero deshonestos, aparentadores, sumisos o arrogantes, e individualistas" (p. 19). Creemos 
tener la democracia más estable de América y ser un país importante en el mundo. Por otra parte, autores recientes como (Bolívar et al., 2001) ponen de manifiesto nuevas fuentes de identificación, como el Divino Niño del barrio 20 de Julio, la selección colombiana de fútbol y el Reinado Nacional de la Belleza.

Con estas propuestas de explicación, los autores intentan tanto encontrar una nueva forma de entender la unificación nacional o lo que hay de ella, como poner de manifiesto la debilidad o el fracaso de los factores duros de identidad o la provisionalidad de las bases sobre las que se cimenta la identidad nacional colombiana. Pero, lo que más habría que destacar es que la mayoría de estos nuevos símbolos de identidad, si no todos, es de origen masivo, un poco más urbano $\mathrm{y}$ tiene una fuerte presencia en los medios, cuando no es un completo producto de ellos.

\section{Marco teórico: mediación y narración mediática}

Para Manuel Martín Serrano (2009), la producción de comunicación es una práctica cultural que se preocupa por generar soporte y relatos sobre el acontecer del mundo y sus cambios. Las organizaciones que dedican su espacio y tiempo a informar sobre sucesos cotidianos se convierten en instituciones, en el sentido de que cumplen funciones en nombre de toda la sociedad y constituyen, por tanto, el punto de vista legítimo y autorizado. Estas instituciones enfrentan el reto de adaptarse a las transformaciones sociales dándoles un tratamiento discursivo. De esta manera, comprometen posturas políticas que pueden estar a favor o en contra de los hechos que se narran.

Martín Serrano (1997) ha señalado que los medios de comunicación masivos (MCM) enfrentan tensiones en el momento de operar como espacios informativos. Por un lado, se enfrentan a un diario reajuste de la estructura expresiva del acontecer $y$, por otro, a la erosión que el cambio social produce en los modelos mediadores de la comunicación.

A la producción de los MCM les ha considerado una doble mediación: por un lado, hacen operaciones de mitificación y, por otro, procesos de ritualización. Nos estamos refiriendo así a las mediaciones cognitivas y a las mediaciones estructurales. Se presenta la mediación cognitiva cuando se opera sobre el relato y es de carácter mítico; y se presenta la mediación estructural cuando se trabaja sobre el soporte y es de carácter ritual.

En un análisis del texto televisivo se tiene en cuenta un relato sincrónico e hipertextual, es decir, los acontecimientos pueden ser narrados en diferentes espacios y temporalidades e incluso yuxtapuestos, pero su carácter puede ser mítico o ritual; en el primero se estudia la manera de presentar la información en un repertorio novedad-banalidad, y en la segunda, en un repertorio relevancia-irrelevancia.

\section{Las sustancias y las formas como mediación}

Se podría decir que entre los "objetos" y los "relatos" (Martín Serrano, 1997, p. 138), equivalentes a expresiones y contenidos, como operaciones de mediación, median todavía dos instancias que llamaremos formas tanto de contenido como de expresión (Eco, 1995, pp. 96-97).

En efecto, los relatos se producen cuando "los datos se relacionan conceptualmente entre sí de una manera determinada" (Martín Serrano, 1997, p. 138), mientras que los objetos aparecen cuando "los datos se expresan de una u otra forma en algún soporte material (por ejemplo, el papel periódico o la pantalla del televisor)" (p. 138). Es en este sentido que los relatos son el contenido del producto comunicativo mientras que el objeto (material) es la expresión de este.

Sin embargo, la relación conceptual entre los datos, que constituye el sistema semántico, es distinta de "la manera" en que se relacionan, pues en este caso se trata de la forma narrativa o argumentativa, de la gramática, lo cual constituye una instancia de mediación más entre el objeto material y el significado. A esta le llamamos forma del contenido.

Por otra parte, el papel periódico o la pantalla del televisor solo devienen objetos comunicativos en la medida en que son la materia (sustancia) expresiva que permite fijar algún tipo de formas expresivas 
(sistemas de señales), ya sean alfanuméricos o imágenes (sistemas sintácticos), que permiten transmitir o comunicar el significado. Estos últimos constituyen las formas expresivas.

Por tanto, para efectos de nuestro análisis, el mito no es equivalente a contenido, sino solo a la sustancia del contenido, es decir, al conjunto de creencias (sistema semántico); mientras tanto, el rito incluye tanto las formas de narrar esas creencias (formas de contenido) como las formas de expresarlas (formas expresivas). En cuanto al soporte material (sustancia expresiva), no resulta relevante para el análisis, pues diversos soportes son susceptibles de albergar diversas formas.

\section{La nación como narración}

Cuando se habla de la construcción de la nación se trata en realidad de un proceso de adopción de dos gramáticas o dos narrativas: por un lado, la narrativa y la gramática de lo universal, que quiere decir occidental, encarnada en la Iglesia y cuyo código de transmisión es la escritura latina; por otro lado, la gramática de la nación, representada por el Estado y cuya codificación básica son las lenguas nacionales, con escritura también latina, llamadas lenguas modernas (Bhabha, 2010).

¿Cuáles son esas gramáticas y narrativas? ¿Cómo se han incorporado en Colombia? Las narrativas pueden ser, en su orden histórico, la religión, la ley, la economía, la gramática, la filosofía y las ciencias, las artes y, finalmente, como parte del relato occidental, los medios de comunicación masivos. La adopción de cada una de estas codificaciones constituye no solo el relato de la nación sino, al mismo tiempo, la educación y la comunicación sobre esta.

En efecto, como se trata de una teleología, todos estos procesos se pueden ver en clave de narrativas: como procesos de evangelización, de reducción o sometimiento, de hispanización, de formación del mercado interno, de alfabetización, de escolarización, de introducción de las ciencias y de las artes, y de introducción o adopción de los medios, todo ello como conformación del Estado-nación.
Para nuestro caso, el Estado-nación está constituido por tres componentes: el Estado, el país y la nación. Y con ello podemos aventurar una definición de Estado-nación, aunque sea provisional, según la cual viene a ser una entidad política soberana que ejerce esa soberanía sobre un territorio llamado país y sobre una población erigida en nación ${ }^{3}$ y, por tanto, toda decisión que pretenda ser política tiene que ser tomada por el Estado o a través de él.

El Estado es la institucionalidad política de unas poblaciones en un territorio. La nación se compone de todos los grupos humanos que por fuerza o de grado están sometidos a dicha institucionalidad. El país se compone de todos los recursos físicos dados por la naturaleza, es decir, territorio continental e insular, subsuelo, áreas marinas y submarinas, espacio aéreo, espectro electromagnético y órbita geoestacionaria, elementos naturales que serían, en principio, inajenables.

Pero, ¿cómo se convierte el territorio en país y cómo se convierten los pueblos en nación? ¿Cuál es papel de los medios en ese proceso?

\section{Metodología}

Entre los múltiples aspectos que toca el problema $y$, por consiguiente, entre los diferentes resultados, en este artículo nos referiremos a lo que constituye una lectura educomunicacional de una muestra de textos audiovisuales, específicamente de los noticieros de televisión, para caracterizar la narración mediática de la nación en dos periodos opuestos: los primeros años (1962) y los últimos noticieros de televisión (2015). La lectura educomunicacional comprende todos los componentes del mensaje, con lo cual hace operativo el marco teórico en un esquema de análisis como el de la tabla 1.

3 Véase la historia del concepto en Hobsbawm (1998, pp. 23-53) y Narváez (2013, pp. 239-246). 
Tabla 1. Matriz de análisis de noticiero de televisión

\begin{tabular}{|c|c|c|c|c|}
\hline Noticia & Expresión & Expresión & Contenido & Contenido \\
\hline $\begin{array}{c}\text { Planos/ } \\
\text { Duración promedio }\end{array}$ & Sustancia & $\begin{array}{l}\text { Forma } \\
\text { rito }\end{array}$ & $\begin{array}{l}\text { Forma } \\
\text { rito }\end{array}$ & $\begin{array}{l}\text { Sustancia } \\
\text { mito }\end{array}$ \\
\hline $\begin{array}{l}1 \\
8 / 0: 10 \\
1.2^{\prime \prime}\end{array}$ & $\begin{array}{l}\text { Recursos } \\
\text { técnicos }\end{array}$ & $\begin{array}{l}\text { Formas sonoras } \\
\text { Formas visuales } \\
\text { Formas alfabéticas }\end{array}$ & $\begin{array}{l}\text { - Sección } \\
\text { - Géneros informativos } \\
\text { - Géneros de opinión } \\
\text { - Géneros interpretativitos } \\
\text { - Sujetos agentes de } \\
\text { la información } \\
\text {-Sujetos objetos de la } \\
\text { información (de quién se habla) }\end{array}$ & $\begin{array}{l}\text { Objetos de la información: temas } \\
\text { (resumen) } \\
\text { Orden/desorden } \\
\text { Ley/delito } \\
\text { Bien/mal } \\
\text { Legítimo/ilegítimo } \\
\text { Encomiable/censurable } \\
\text { Exitoso/fracasado } \\
\text { Resultado: el gobierno, } \\
\text { como instancia legítima, } \\
\text { restablecerá el equilibrio }\end{array}$ \\
\hline
\end{tabular}

Sin embargo, para efectos de esta presentación solo tomaremos el último componente, es decir, la sustancia del contenido, en términos semióticos, o el mito. Se trata de hacer un resumen de cada noticia como conflicto, es decir, alguien que representa el lado positivo, establecido, normal, etc., y alguien que representa el lado disruptivo, negativo, anormal. En una palabra, la dicotomía redundancia/entropía, en la que la entropía es lo informativo porque hace la diferencia. Aún así, el papel de los medios como institución es volver a la redundancia, a la isostasia, es decir, al orden, a la estabilidad.

Los resultados se obtienen de la descripción del contenido de una emisión del noticiero de 1962 y una fracción más o menos equivalente de una emisión del Noticiero RCN del 16 de junio del 2015. De ella se obtienen, en el primer caso, las cuantificaciones que aparecen en la tabla 2 , y en el segundo, una reconstrucción del relato.

\section{Las sustancias del contenido (mito): noticiero Actualidad Panamericana, 1962}

El equilibrio tanto en número de noticias como en tiempo (tabla 2) entre temas económicos, reducidos prácticamente al éxito empresarial, políticos, reducidos a asuntos que tienen que ver con el poder central, e internacionales, que también son políticos y económicos, habla de un contenido, de un mito, según el cual la nación se compone principalmente de instituciones económicas y políticas, es decir, del Estado y las empresas como los dos grandes entes que representan la nación, por tanto, las que tienen el deber y la responsabilidad de guiar a la población, de mantener el orden y la armonía y de garantizar la supervivencia de la comunidad imaginada (Anderson, 2005) llamada Colombia. Por tanto, también son las que merecen el mayor respeto, acatamiento $y$, sobre todo, una suerte de inmunidad frente a los ataques posibles de los enemigos de la sociedad, que vendrían a ser quienes se opusieran a dicha preeminencia.

La representación del territorio nacional es de las más restringidas; en 10 de las 11 piezas que componen la emisión la región que aparece es Bogotá y solo en una se da cuenta de un acontecimiento fuera de la Sabana de Bogotá, la Feria Agropecuaria de Medellín. Como fondo de esta imagen se escucha música folclórica de la costa Atlántica, con lo que el número de regiones asciende a tres, pero esta última de manera difusa, a través de una asociación más simbólica que icónica, pues no hay imágenes del territorio caribeño (en otros noticieros aparecen ferias ganaderas en el Caquetá, por ejemplo, pero como si fueran territorios de frontera). 
Tabla 2. Noticiero Actualidad panamericana. El mito. Los temas

\begin{tabular}{|l|c|c|c|c|c|c|}
\hline \multicolumn{1}{|c|}{ Clase noticias } & Orden de noticia & $\mathbf{N}^{\circ}$ noticias & $\%$ & Tiempo total & $\%$ & Tiempo promedio \\
\hline Corporativa & 1 & 1 & 8,3 & 10 & 1,5 & $10 "$ \\
\hline Economía & $2,6,8,10$ & 4 & 33,4 & 215 & 32,6 & $54 "$ \\
\hline Política nacional & $3,5,9$ & 3 & 25,0 & 210 & 31,8 & $70 "$ \\
\hline Internacional & $7,11,12$ & 3 & 25,0 & 195 & 29,6 & $65^{\prime \prime}$ \\
\hline Social & 4 & 1 & 8,3 & 30 & 4,5 & $30 "$ \\
\hline \multicolumn{1}{|c|}{ Total } & & 12 & 100.0 & $660 "$ & 100,0 & $55^{\prime \prime}$ \\
\hline
\end{tabular}

Como dijimos, la narración indica que esta es una nación de sujetos institucionales, empresariales e internacionales. Pero desde el punto de vista puramente humano, todos ellos son hombres, blancos o mestizos, ilustrados, poderosos y adinerados, como el presidente (piezas 3, 5, 9), parlamentarios (pieza 9), ministros (pieza 11), poetas (pieza 5), gerentes (pieza 6 y 8), militares y obispos (pieza 9), y ganaderos y jinetes (pieza 10). Este último caso es el que se resalta de Antioquia, o mejor, del tipo antioqueño, y hace una diferenciación étnica ligada al territorio y a la actividad económica como distintivos de estratificación regional de la población colombiana.

Cuando aparecen las mujeres como protagonistas, estas son de la misma condición socioeconómica $\mathrm{y}$ racial, pero no tienen funciones institucionales o empresariales, sino funciones de caridad, como en la pieza 4 , además ejerciéndolas sobre otras mujeres en condición de desamparo y como actividad social apartada de funciones de poder. En otros noticieros del mismo año, el protagonismo de las mujeres tiene que ver con los reinados y con la promoción de actividades artísticas también ligadas a la beneficencia.

El problema de las clases sociales solo se menciona explícitamente en la pieza 3, cuando se habla del desfile "de personas pertenecientes a todas las clases sociales del país". La alusión no tiene por objeto relevar que existen clases, sino, por el contrario, poner de manifiesto que ese es un problema inexistente por cuanto el presidente tiene el reconocimiento de todos. Cuando aparecen los pobres o los campesinos lo hacen en calidad de adherentes al presidente, al gobierno, a las instituciones, o como beneficiarios de la caridad femenina o destinatarios de la "nobleza" de espíritu del poeta que quiere fundar un poblado (en otros casos, como bendecidos por la bondad de los sacerdotes, como en otro noticiero donde se inauguran casas del Minuto de Dios, o como redimidos por la mano civilizadora de la alianza para el progreso en la inauguración del barrio Kennedy o como receptores de la justicia con que actúa Bavaria al construir casas para los obreros). En todo caso, no aparecen como sujetos sino como objetos de las buenas o legítimas acciones de los poderosos.

Los antioqueños aparecen en la narración noticiosa como promotores de ferias agropecuarias, como finqueros y como chalanes, lo que los diferenciaría étnica, cultural, económicamente de los bogotanos. Las mujeres (de clase alta por supuesto) aparecen como las que agencian la caridad hacia los más necesitados. Los pobres se muestran como merecedores de la caridad, la ayuda, la beneficencia, etc., pero no como sujetos de derechos. En todos los casos, la narración parece sugerir que este es el lugar legítimo que le corresponde a cada grupo en la estructura de la sociedad colombiana, que es lo que garantiza su armonía y funcionamiento. Desde luego, los afrodescendientes y los indígenas no tienen lugar en esa estructura social.

Justamente esta manera de narrar la nación como unitaria, la de las instituciones legítimas que avalan el dominio de las gentes de bien, es la que hace que la estructura del noticiero no necesite reconstruirse desde la lógica inicialmente propuesta en la matriz de análisis como orden/desorden, ley/delito, bien/mal, 
legítimo/ilegítimo, encomiable/censurable, exitoso/ fracasado. Todo el relato aparece un conjunto de casos de personajes de bien, de orden, cumplidores de la ley, de acciones encomiables, de emprendimientos exitosos y, como sumun, que están en posiciones legítimas de dominación.

No hay en la narración alguien que represente lo contrario, excepto una mención casi inadvertida al gobierno militar anterior a 1958 (pieza 9). No existe oposición política ni mucho menos armada. No existe la protesta social. No existe nada que pueda dar cuenta de las contradicciones y menos de las propuestas alternativas de sociedad; tampoco existen los desórdenes normales de toda sociedad. La violencia cotidiana, el delito, lo ilegítimo, lo censurable y el fracaso son borrados de la vida social, pues el ideal del Frente Nacional consiste precisamente en que las clases responsables de la violencia puedan dominar en paz. Lo contrario (los pobres, los campesinos y las mujeres) es subsumido como la parte subordinada de la estructura, pero, sin embargo, necesaria, además de ser una condición aceptada por los sujetos que la sufren. Lo diferente (los afrodescendientes, los indígenas, los extranjeros) simplemente no existen. El mito, el derecho a dominar de quienes efectivamente dominan, aquí no se impone como la mejor versión sino como la única versión posible. En eso consiste la mitificación como mediación cognitiva.

\section{Sustancias de contenido (mito): Noticias RCN, 2015}

En el caso de los noticieros del 2015, el esquema agonístico y antagónico representado en la dicotomía bien/mal, legítimo/ilegítimo, orden/desorden, ley/delito, encomiable/censurable, exitoso/fracasado es completamente claro, ya no solo en términos del éxito y el fracaso, como ideal capitalista, sino como amigo y enemigo.

En efecto, en la muestra actual, compuesta de un fragmento de titulares y 17 noticias, es clara la existencia de un enemigo identificable que son las FARC en 10 de los 17 casos (piezas 5-11, 14, 15, 17). No solo son la mayoría de las noticias sino las del primer bloque. Pero no se trata solo de un enemigo del Estado, de las instituciones, como cuando ataca a la fuerzas militares y de policía, sino de un enemigo de la población, como en el caso de los habitantes del corregimiento El Mango, pues, según el relato, son constreñidos por las FARC a enfrentar a la policía o son manipulados por la guerrilla, con lo cual actúan más como rehenes que como sujetos (pieza 6). Si lo hicieran autónomamente, serían aliados de las FARC, es decir, enemigos.

Pero las FARC no solo son el enemigo del Estado y la población, sino del territorio, pues son sus agresores a raíz de la contaminación causada a la vegetación y a las aguas a través del derrame de petróleo producido por sus atentados contra los oleoductos (pieza 11). En una palabra, las farC son el enemigo total de "la patria", que es el nombre sentimental con el que se identifica el Estado-nación. Aun así, la satanización no termina ahí, sino que también se presenta a dicha organización como enemiga de la humanidad entera, pues se resalta que deberán responder por la comisión de delitos de lesa humanidad, con lo cual la lucha contra las FARC no es solo por la patria sino por toda la humanidad (pieza 14).

El segundo enemigo identificable es Venezuela (piezas 2-5); se presenta a su gobierno como una amenaza directa al territorio y a la población de colombianos a través de la rectificación de un mapa que altera los límites fijados por un tratado anterior entre Colombia y Venezuela. El vicepresidente de Colombia invoca la unidad de todos los colombianos, incluyendo a la oposición, para defender a la patria.

A propósito, este llamamiento se debe a que, aunque no está en este relato, en la misma noticia, también ubicada como número uno en el Noticiero de Caracol, aparece la figura del expresidente Uribe situado del lado "correcto", en el primer término de la dicotomía, y situando a su vez al presidente Santos del lado opuesto, o sea prácticamente en el mismo lugar de Venezuela y de las FARC. Esto significa que no solo estar de parte del enemigo, sino incluso dialogar con el enemigo, convierte a los agentes en enemigos de la patria. 
Por otro lado, en la pieza 17 se construye un relato antagónico entre el Congreso de los Estados Unidos, de mayoría republicana, y el gobierno presidido por los demócratas, en el cual se cuestiona el apoyo de dicho gobierno al proceso de paz en Colombia. En este caso, la derecha republicana aparece "del lado correcto de las cosas", mientras el gobierno de Obama aparece del lado incorrecto, es decir, en el mismo lugar del gobierno colombiano, el venezolano y, por extensión, de las FARC, pues se considera la negociación una concesión al terrorismo. El relato va pues escalando en la construcción del enemigo: desde las Farc se pasa a Venezuela, luego se pasa al gobierno colombiano que quiere negociar la paz con los enemigos y sus aliados (Venezuela), hasta llegar al gobierno de Obama que apoya dicha negociación.

En todos los casos, sin embargo, la solución, la restauración del equilibrio, reside en la acción de las autoridades y las instituciones, ya sea en la ayuda, el diálogo o la acción de la fuerza armada del Estado.

Aun así, siempre queda una respuesta implícita en el relato que a veces se hace explícita: el relato va encaminado a lo que debería ser el final construido consecuentemente con la lógica de este, o sea hacia la aplicación de la ley y la fuerza a toda manifestación opositora, puesto que si estas no son de la guerrilla son de gente manipulada por la guerrilla o son partidarios de ella; seguidamente, respuesta militar contra Venezuela y, finalmente, alianza con los sectores guerreristas del Congreso de Estados Unidos.

También aparecen situaciones fuertemente conflictivas cuando se trata de agentes delincuenciales "no políticos" como en el caso de los narcotraficantes del clan Úsuga, quienes serán extraditados a Estados Unidos (pieza 13). Asimismo, se muestra el llamamiento a interrogatorio de algunos generales de la fuerza pública (pieza 16), quienes estarían incursos en delitos como las ejecuciones extrajudiciales llamadas "falsos positivos". En este caso, aunque se trata de episodios de delincuencia, no se los considera de antemano culpables (se considera que "habrían enviado más de 73 toneladas" de cocaína; se los acusa de hechos ocurridos "supuestamente" en Antioquia), con lo que no solo se presume su inocencia sino que no se los considera en rigor enemigos de la patria ni de la humanidad.

Este doble rasero se explica en parte por el carácter antisistémico del delito de las FARC y el carácter funcional al sistema de los dos tipos de delitos imputados a estos últimos. Aunque no confesados, el narcotráfico dinamiza la economía y ha mantenido una balanza de pagos estable en Colombia durante muchos años. Los métodos ilegales en manos de la fuerza pública han permitido a veces éxitos en la lucha contra la insurgencia, por tanto, serían un mal necesario.

Es sintomático que el relato se construya con 17 episodios de los cuales 12 tienen que ver con delitos (políticos y "no políticos", pero todos relacionados con el conflicto interno) y cuatro con enemigos externos (tres con Venezuela, uno con Estados Unidos) y solo dos con una historia de éxito, la de Juanes y su participación en la visita del papa a Estados Unidos.

¿Quiénes son finalmente, según este relato, los personajes de la vida nacional? Por un lado, los agentes institucionales, desde el presidente y los ministros, hasta los agentes de la fuerza pública y de la justicia, especialmente estos últimos, es decir, los agentes de la represión. Por otro lado, los gobernantes extranjeros que fungen como una especie a la vez de amigos ambiguos (el presidente de Venezuela y el de Estados Unidos), al respaldar los diálogos. Finalmente, los delincuentes, tanto comunes como políticos, lo cual incluye algunos agentes institucionales. El único agente que se sale de este cuadro es un integrante de la farándula, quien constituye un caso de éxito opuesto a todas las historias de fracaso. Los agentes sociales, los pobladores, los campesinos, los indígenas y los afrocolombianos son siempre víctimas, tanto los del Cauca como los de la Guajira o los soldados rasos, pero no víctimas del sistema, de las instituciones o de la sociedad, ni de la guerra, sino de los enemigos (de Venezuela o de las FARC). Los empresarios, los sindicalistas, los trabajadores, los artistas, los intelectuales y los maestros no son parte de este relato.

¿Y cuáles son los territorios? En primer lugar, los de la Guajira, pero por ser limítrofe con Venezuela, solo ahí son parte fundamental de Colombia; 
los del Cauca, por referencia a las FARC; los de Norte de Santander, por la misma razón; los de Nariño, por los atentados de las FARC contra los oleoductos; los de Antioquia, por el caso del clan Úsuga y los falsos positivos, es decir, por las acciones de los delincuentes "no políticos". En segundo lugar, aparece Bogotá como sede de la representación institucional, del poder. El país se dividiría entre las zonas del poder central y las zonas de conflicto. El resto parece no existir. Entre centro y periferia no parece haber regiones normales.

\section{Conclusión: del infractor inexistente al enemigo omnipresente}

En cuanto al discurso, en el noticiero de 1962 es bien claro el predominio del contenido trascendental sobre el situacional. Se transmiten grandes ideales como patria, democracia, república, moral, $y$, sobre todo, progreso y desarrollo. Eso explica en buena parte la importancia, no solo en la publicidad sino también en las noticias, de las empresas y los empresarios.

Lo más evidente es la presencia de los agentes empresariales como sujetos-objeto de la información en una proporción más importante en 1962 que en los noticieros actuales, y dentro de los empresarios, los de la industria, más que los del sector financiero y el comercial (estos dos aparecen juntos en la noticia sobre el balance del Banco del Comercio, dedicado justamente a financiar actividades comerciales y a estimular el consumo individual y familiar). Esto corresponde a una época en la cual el país está entrando en un nuevo intento de modernización, entendida como industrialización, urbanización, escolarización y, sobre todo, ampliación del mercado interno. En el propio cabezote del noticiero Actualidad panamericana se destaca este como una producción colombiana hecha por una empresa colombiana y con técnicos colombianos.

Es claro el contraste entre el país de la paz creado por el Frente Nacional que narran los noticieros del año 1962 y el país del conflicto que narran los noticieros actuales; entre el país de las instituciones estables y de las empresas nacionales de los primeros y el país de la fuerza pública y los delincuentes amenazantes actuales; entre el país de las regiones que producen (ganaderas, agrícolas, industriales, comerciales) y el país de las regiones en conflicto. Es evidente el contraste entre el país que entra en la modernización y el que está permanente amenazado, entre el país que exhibe fuertes instituciones republicanas y el que exhibe la necesidad de una fuerte militarización para mantenerlas.

Es por esto que podemos decir que pasamos del infractor inexistente en los noticieros de 1962 al enemigo omnipresente en los actuales, de la autocomplacencia en 1962, al estado de amenaza manifiesta en la actualidad. Esto nos mantiene en estado de alerta y de defensa permanentes, pero lo que parece sugerir el relato actual es que lo que nos falta es pasar de este estado a uno de ataque definitivo para eliminar al enemigo.

\section{Referencias}

Acosta, L. F. (2004). Celebración del poder e información oficial. La producción cinematográfica informativa de los Acevedo (1940-1960). Historia Crítica, 28, 59-80.

Anderson, B. (2005). Comunidades imaginadas. Reflexiones sobre el origen y la difusión del nacionalismo. México: Fondo de Cultura Económica.

Bhaba, H. K. (2010). Nación y narración. Entre la ilusión de una identidad y las diferencias culturales. Madrid: Siglo XXI.

Bolívar, I. et al. (coord.) (2001). Belleza, fútbol y religiosidad popular. Bogotá: Mincultura.

Carrillo Hernández, A. M. y Montaña Ibáñez, A. M. (2006). Vértigo y ficción, una historia contada con imágenes. Noticieros de televisión en Colombia, 1954-1970. Signo y pensamiento, xxv(48), 135-147.

Eco, U. (1995). Tratado de semiótica general (5a ed.). Barcelona: Lumen.

Herrán, M. T. (1991). La industria de los medios de comunicación en Colombia. Bogotá: Fescol.

Hobsbawm, E. (1998). Naciones y nacionalismo desde 1780. Barcelona: Crítica.

López de la Roche, F. (2004). Presentación del dossier sobre historia de los medios de comunicación social y el periodismo en Colombia. Historia Crítica, 28, 7-26. 
Martín Serrano, M. (1997). La mediación de los medios. En J. Martín-Barbero y A. Silva (comps.). Proyectar la comunicación (pp. 137-156). Bogotá: Unal-Tercer Mundo.

Martín Serrano, M. (2009). La producción social de comunicación. Madrid: Alianza.

Narváez, A. (2013). Educación y comunicación: Del capitalismo informacional al capitalismo cultural. Bogotá: Fondo Editorial Universidad Pedagógica NacionalDoctorado Interinstitucional en Educación.

Narváez, A. y Arbeláez, O. (2013). Educación mediática y nación en Colombia. Informe final. Bogotá: CIUPUPN. Inédito.

Narváez, A. y Arbeláez, O. (2014a). Nación y narración mediática: El relato publicitario de la RCN y Caracol Radio. Comunicación, cultura y política, 5(2), 101-123.
Recuperado de: http://edicionesean.ean.edu.co/index. php/es/revistas/revistas-impresas/comunicacion-cultura-y-politica/23-publicaciones/399-revista-comunicacion-cultura-y-politica-volumen-5-numero-2-julio$\mathrm{y}$-diciembre-de-2014

Rincón, O. (2001). Colombia: Marca no registrada. En O. Rincón (coord.), Relatos y memorias leves de nación. Serie Cuadernos de Nación (pp. 11-39). Bogotá: Mincultura, 2001.

Uribe Sánchez, M. (2004). Del cinematógrafo a la televisión educativa: el uso estatal de las tecnologías de la comunicación en Colombia (1935-1957). Historia Crítica, 28, 27-58.

Zapata, M. y Ospina, C. (2005). Cincuenta años de la televisión en Colombia. Una era que termina. Un recorrido historiográfico. Historia Crítica, 28, 105-126.

\section{Para citar este artículo}

Narváez, A., y Romero A. (2017). La nación en la televisión informativa colombiana: 1960 y 2015. Del infractor inexistente al enemigo omnipresente. Folios, (46), 55-65. 